\title{
Chemical and Structural Changes in the Movement of Water, Neces- sary for Life of Nature
}

\author{
Arkady Styrkas* \\ Academy of Sciences of Russia, Institute of Solid State Physics of Academy of Sciences of Russia, Russia
}

"Corresponding author: Arkady Styrkas, Academy of Sciences of Russia, Institute of Solid State Physics of Academy of Sciences of Russia, Russia. Tel: +74965223261; Email: astyrkas@issp.ac.ru

Citation: Styrkas A (2018) Chemical and Structural Changes in The Movement of Water, Necessary for Life of Nature. J Fish Aqua Dev: JFAD-139. DOI: 10.29011/2577-1493. 100039

Received Date: 18 April, 2018; Accepted Date: 30 April, 2018; Published Date: 07 May, 2018

\section{Summary}

A study of the behavior of water during its movements under mechanical shaking is presented. It is shown that rhythmic shaking of water with $1 \mathrm{~Hz}$ causes the same rhythmic effects in a periodic $[\mathrm{H}+]$ growth and products with higher positive potential. Discusses the role of water motion in Nature - alive and inanimate.

Keywords: Mechanical Movement; Nature Processes; Potential; Water; "Walking Opinion"

\section{The Preface: Hymn to the Sciences and its Engines}

The amazing thing is science. It is intended for search of truths, for understanding of natural phenomena, not to disturb the Nature to live and give life to the Earth. But in all ages it is the "science" absurd, "walking views" prevents this by destroying the thinking of researchers, imposing the usual views. Socrates drank a Cup of toxin, Archimedes during mathematical calculations killed a Roman Legionnaire. Reviewers of prestigious journals heard by absurd verdicts, the editors somehow appreciate them, contrary to the sense. report that are able to change $\mathrm{pH}$, and about $\Delta \mathrm{E}$ told to read the $\mathrm{ABCs}$ of electrochemistry. And so not in one magazine, but as under carbon paper. Than more often repeat the walking opinions and refer to the authorities, the more stable their position in the editorial and editor. Interestingly, more than half of Einstein Rosen believe that he was given the Nobel prize for the theory of relativity and don't even know what it is a paraphrase of the 1 law of the photoelectric effect by A. G. Stoletov, replacing the "directly proportional" to the "Linear Relationship", demonstrating thus manifested the depth of his new knowledge in mathematics. If the facts do not climb into the «theory», so much the worse for the facts. «scientific» walking opinions tenacious. Einstein was supposed in 1927 to give the Nobel prize, but NOWHERE to find evidence of his «Theory». Obedient Nobel the Committee gave bonus for retelling in the language of quanta in 1905 contents of 1 Law of the photoelectric effect, one of the three opened A. G. Stoletov more than 30 years before. And now more than 100 years, spreading all sorts of praise this genius of all time and one of the folk, the necessary attributes of success in the «Sciences». And legions of scribes painted books about geniuses, hurrying to praise something for which no one dared to award the Nobel prize. Pais in the book «Biography of Einstein» found particularly brilliant reception of praise. Describing the fact, when Poincare asked for advice on whether to take teachers privatize the Poincare equation, Poincare strongly advised not to do this stupidity. Well, it would seem, what Committee gave novelette for retelling in the language of quanta in 1905 contents of concept of the 1 Law of the photoelectric effect, one of the three open A. G. Stoletov more than 30 years before. And here more than 100 years, spreading all sorts of praise this genius of all time and one of the folk, the necessary attributes of success in the «Sciences». And legions of scribes painted books about geniuses in haste to praise what did not dare to give the Nobel Prize. Pais in the book «Biography of Einstein» found particularly brilliant reception of praise. Describing the fact, when Poincare asked for advice on whether to take teachers who privatize the Poincare equation, Poincare strongly advised not to do this stupidity. Well, it would seem, what the case readers to Poincare, who "did not understand" his own equations, but Pays immediately writes: «Soon Poincare died.» WELL, don't you dare speak out, if you want to live! Then «accidentally» listed a number of researchers who valued a sober genius, about them also said: «soon they all were dead» draw conclusions, PICES is only hinted at. Such examples y science a lot. Newton brought Menshikov diploma of the Royal society. President of the Academy of Sciences Admiral Latke, "chemistry" expert, his two votes were sub arterial D.I. Mendeleev and «chose» Brillstein. It is surprising that at all 


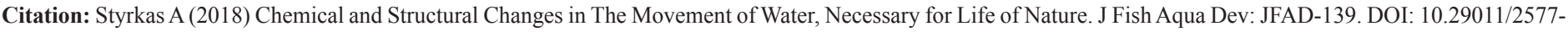
1493. 100039

times there were seekers of truth anyway. They were burned at the stake, slaughtered in other ways fighters with pseudoscience. But folk wisdom is able to discern the truth and parrot. So, for example, built by the most skillful shipbuilders the ship «Titanic» was lost with the victims in his first going to sea. And led by a Lieutenant by V.M/Golovnin the sloop «Diana» twice successfully escaped from captivity scientists Saxons and Japanese, having studied real phenomena. That is to be surprised.

\section{The Influence of Water Movement on Biological Processes}

Let us turn to the real facts, not the theoretical interpretations of the walking opinions, because the subject of the study is the role of water movement in life. Observational peoples have long understood that life gives water to Nature. All living things consist of $86 \%$ water and is in constant movement. But when the Ice age reigned on Earth, the life of the ice crust could not be. Interplanetary processes of volcanic eruptions emitted their products of activity. Gases created a greenhouse effect, ice melting, and liquid water are constantly moving away from external sources of movement. The sun was created by the constant current, the attraction of the moon gave tides, the masses of the stars is constantly caused oscillatory movement of the waters of the seas with a frequency of $1 \mathrm{~Hz}$. It turned out that the water is not an element but a compound $\mathrm{H}_{2} \mathrm{O}$. 1. According to Engels: life is a «Way of existence of protein»! If the heart stops, the movement of the body, it dies, But the protein does not disappear, there are. Proteins have plants there is no. and they live. Until it moves water from the roots. 2. People have long known that the mushrooms grow actively. But they live in the swamps, where water and green stuff, and a lot of oxygen. 3. Jellyfish is $96 \%$ water. What is left for the proteins, fats, carbohydrates, and salts? 4. Pets, going out on pasture with fresh dew, first, go to the river with running water, and only after drinking it in the flowing water going to the meadow. Cows did not read reviews and do not know the walking opinions, but their natural instinct directs them along the natural path. 5. Interesting analysis of gases in different areas of the United States, with smog or without it, gave a constant content of $\mathrm{H}_{2} \mathrm{O}_{2}$ in rainwater. The content of oxides of $\mathrm{N}, \mathrm{S}$ and other oxides of variables widely. Authors believe that the cloud fluctuations are satisfied with oxygen resulting in $\mathrm{H}_{2} \mathrm{O}_{2}[1,2]$. The authors mistakenly attributed the phenomenon of dissolution of $\mathrm{O}_{2}$ in the clouds at their fluctuations and the formation of this peroxide. The fact that the height in the sky, the concentration of $\mathrm{O}_{2}$ is low, cold is still below its solubility, so $\mathrm{H}_{2} \mathrm{O}_{2}$ go into more stable $\mathrm{O}_{2}$, but not Vice versa. But they noted the role of the movement. In the light of the studied mechanochemical processes, this result is not unexpected, as below.5. He People know that about waterfalls breathe easier, as if the friction from the ice floes. Easier than in the woods or swamps, where many green plants, forming $\mathrm{O}_{2}$ by photosynthesis, providing them with Land. Without denying the great importance of photosynthesis for life on Earth, this statement cannot be accepted. First of all, the reaction of photosynthesis $\mathrm{nCO}_{2}+\mathrm{nH}_{2} \mathrm{O} \rightarrow \mathrm{n}\left(\mathrm{CH}_{2} \mathrm{O}\right)+\mathrm{nO}_{2}$ how much will be absorbed by the $\mathrm{CO}_{2}$ and $\mathrm{O}_{2}$ are allocated, Exactly the same back for the same reaction $\leftarrow$ when the plant dies, and therefore the balance of $\mathrm{CO}_{2}$ and $\mathrm{O}_{2}$ will not change one iota. Not to mention the fact that water covers $71 \%$ of the Earth. Of the remaining half of the territory is in the polar regions without plants and in the rocks and deserts, the rest half of the time falls on the dark, half - on the cold seasons without photosynthesis. And water fluctuates constantly. The variability in provide the presence of $\mathrm{O}_{2}$ and other products of the movement of water, essential for life on Earth. 6. Fish, the inhabitants of the waters, there are almost no swamps, they live in conditions of fluctuations of water. In the body of any living creature, most of the water, but we know very little about its critical role in the life of Nature, and she struggles with the troubles that it carries the crown of her creation, living common to all views walking views, believing them, not wanting to reflect on their absurdities. When the sea spilled oil, the fish is not enough $\mathrm{O}_{2}$. Spilled oil dampens vibrations of $\mathrm{H}_{2} \mathrm{O}$, nothing produces $\mathrm{O}_{2}$ and $\mathrm{H}_{2} \mathrm{O}_{2}$ for the life of Nature, green friend including. The fish are looking for in the alien environment of salvation and we all believe, as taught us that the $\mathrm{O}_{2}$ in the water from the air, and not Vice versa. Respecting the photosynthesis for the whole benefit of it, someone else's merit to ascribe to him is not necessary. Fish are even thrown out on land in search of the necessary substances for life, without having for their production of moving water. 7. Naively believing that Nature and its laws are the same, risking once again to get a label of pseudoscience, I will give the result of a simple, accessible chemical laboratory, experience, again violating the "scientific" official sections of Sciences for their convenience. Held a simple, affordable chemical laboratory experience. Two Petri dishes of the same size filled with the same quantity of dry soil. It is in 3 parts, consists of turf and peat land and 1part sand. Near a window without direct sunlight. Cups feature next, and they put the same dry leaf buds, roots and all. Water for the reference experiment is prepared from melted snow thermosetting it at $18^{\circ} \mathrm{C}$, which hold the glaze in equal amounts different water. Water intended for watering of test specimens within 30 min using a piston dispenser, is gaining a given dose of water from the vessel and introducing her back with a frequency of $1 \mathrm{~Hz}$ is subjected to fluctuations. Changes $\Delta \mathrm{E}$ Pt electrodes during single and prolonged oscillations recorded on H301 against the SCE. (1) the Cup is placed the subjects of kidneys. For a given mode, the water temperature in the vessel rises by $0,1^{\circ} \mathrm{C}$. Therefore, it is pre-adjusted to $17.9^{\circ} \mathrm{C}$. So both types of water after the cessation of the oscillations have equal temperature. Portions of $20 \mathrm{ml}$ water the kidneys once every three days in 21-day experience complete. Samples of experimental and control shown in (Figure 1) and (Figure 2). Subjected to fluctuations in water gave plants and products, and building material from damaged structures of polymers, willingly accepting the forms of the 
matrix, in this case the plant itself. Moving water not only give the desired products of chemical reactions, but too in the polymer structure, depressed by restructuring and is able to build the desired matrix in the body, to patch its holes. Resting water of these qualities has not, it is less mobile in this respect.

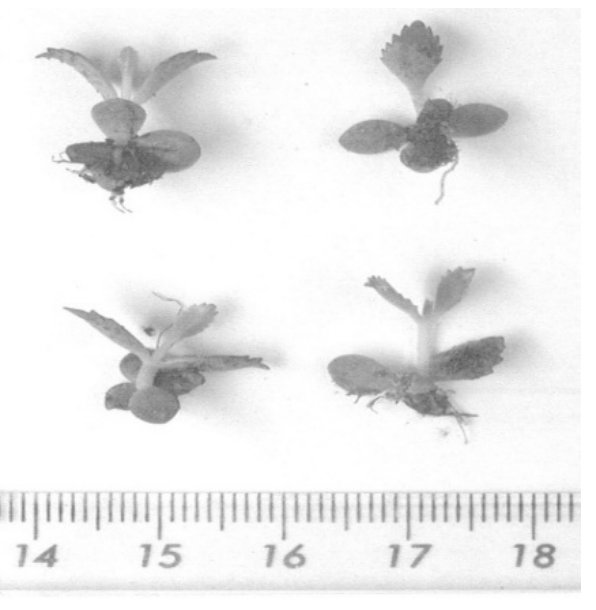

Figure 1: It shows the resulting new leaves.

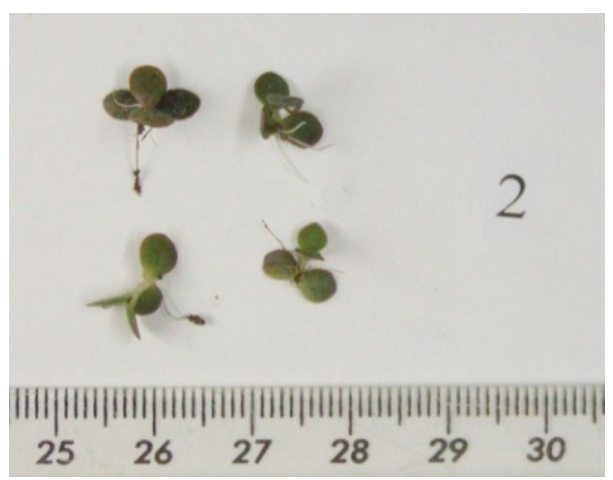

Figure 2: They aren't on the test (Figure 2), although they, too, have grown, but considerably behind in growth even in such a short period of time.

A simple experiment illustrating the role of water movement on the example of the development of Kalanchoe, observable in the laboratory.

\section{First Resume}

"Life is the existence protein bodies - falsity walking opinion". The jellyfish is $95 \%$ of water, proteins, fats, carbohydrates, salts - where? The herbs, trees, vegetables, and fruits generally have no protein. So they inanimate? Every life form requires water. The constancy of $\mathrm{H}_{2} \mathrm{O}_{2}$ in moving water due to reactions of water, not the absorption of $\mathrm{O}_{2}$ depleted atmosphere for them. Conversely, when vibrations arise, these substances essential to life. An environmental disaster when the oil spill in the "calming" waves, stop supplies from vibrations. The water is not filled up by them, and fish are dying without them. Rain gives to plants the necessary substances and building material in the form of polymers with defects. The expression "Grow like mushrooms after rain" perceive that mushrooms need in the moving water. They live in the rich wet soil of swamps after the rain grow harder. They need not just water, but moving, rich need for life products. Life originated in the sea. Wave vibrations with a frequency of $1 \mathrm{~Hz}$ and pulse beings $\sim 1 \mathrm{~Hz}$, it is hardly by chance similar. And the name of the creator of the unit of frequency is the Heart! Coincidence eloquent. "The life - movement is animated water" (Leonardo da Vinci) Almost word for word: life is movement of structured water. Death, cardiac arrest, blood of the engine. Blood, that is - Water! Capillaries provide the system for blood circulation within a living organism. Blood consists of is $86 \%$ of water. There are about 2000 capillaries in a $1 \mathrm{~mm} 3$ of a skeletal muscle of a human and blood, passing through them, comes in contact with $0,5 \mathrm{~m}^{2}$ of surface of their internal walls. The surfaces properties of water are different from the volume ones. For example, there is a thin layer of water on the interface of ice with other phases [3]. The $\tau$ (lifetime) of the structural form of water in thin surface layers can substantially exceed that in the bulk. A similar example of the role of water (see below in physics) - gives the transformation $\beta \mathrm{Sn} \rightarrow \alpha \operatorname{Sn}[4,5]$ under moving water.

The clusters are in the current of the water a variety of forms, but their restructuring is going in the specified direction in the presence of external bodies, for example, biological substances, including in midget doses. This is based on the homeopathy. Molecules of substances surround the polymers of the water, adapting to their structure, so in the absence of them reproduce the therapeutic effects. Peculiarities of structure of water and its behavior under weak mechanical movement in inorganic systems could be used for explanation of processes in complex living organisms, to understanding of efficiency of medical treatment by means of weak energy influence. The low level of power of EM radiation of $\mathrm{mm}$ range, the influence on an organism in process Microwave Resonant Therapy (MRT) is effective, is enough. The system of the blood circulation in the organism with a developed capillary surface provides existence of preferential directions for protons motion along chains of hydrogen bonds in the thin surface layers of water. Pathologic processes in an organism appear because of the disturbance of proton conductivity in capillaries. It is possible that quantities of energy necessary for their recover may be negligible in comparison with the potential barrier between two equilibrium positions of a proton in the chain. Weak fields affect the properties of the membranes, the processes in cells, to long-range interaction communication functions of the system organisms. Water with great speed betrays the signal of injury and external influences in the system of decision-making for restoration of violations. The mobile network of hydrogen bonds provides the speed and action at a distance in the transmission of information. Energy for the 


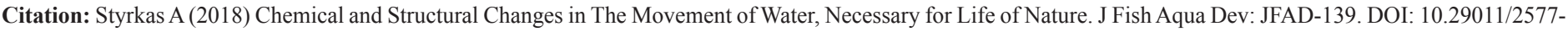
1493. 100039

recovery of self-consistent vibrations in the H-bonds system (and, consequently, for process of metabolism) is not necessary at all. The channels of proton conductivity provide long-distance action because of the soliton mechanism [3] of energy migration. It is probable that energy in released in locations of damages of the ordered networks of the H-bonds and recovers them. These weak influences can't change the character of H-bonds in a correctly functioning structure of near-surface water. It should be mentioned that the blood capillaries characteristic for skin, skeletal muscles, muscular system, heart, cerebrum, organs functions of providing contact with external environment.

\section{Ramy Mahmoud The Water Movement at Oth- er Nature Processes}

Similar examples of the influence of water movement visible in almost all-natural phenomena. Probably, the study of water motion would allow to clarify the role of the mechanical effects of water in natural processes and give answers to many questions in nature is interconnected, and the division of its laws on physical, chemical, biological and geological is a consequence of our limited knowledge. The Nature is indivisible. In order to check the hypothesis about the character of the «behavior» of water at mechanical movement we performed measurements of Red-Ox potentials.

\section{Geological Processes in The Movement of Water}

V. I. Vernadsky called the mineral water as a creator of landscape and processes on the planet. Movement of water to create products that affect the physical properties, gives life, heals, nurtures, creates geological masterpieces, mountains and continents, and mighty rivers in the rocks, the threat of a tsunami, move the continents, currents that regulate the planet's climate. The role of water and its movement in geological processes is huge. There is the constancy of the $\mathrm{H}_{2} \mathrm{O}_{2}$ content in rain waters from different areas with all sorts of atmospheric composition with significant differences in content of various oxides. Believed that shake of water in the clouds leads to the dissolution of $\mathrm{O}_{2}$ from atmosphere (however, lower concentrations than at the surface!) and the formation of peroxide. It is proved that the mechanochemical decomposition of water with a gap of a pair of electrons $\mathrm{H}: \mathrm{O} \div \mathrm{H}$ gives the radicals $\mathrm{OH}^{*}$ and $\mathrm{H}^{*}$ that give the peroxide, the excess is decomposed, giving $\mathrm{O}_{2}$ to the Earth, $\mathrm{H}_{2}$ upper layers of the atmosphere. On the Earth has not dried up $\mathrm{O}_{2}$ due to the energy of the Cosmos, constantly influencing to the movement of water. Idea [6] about the abiogenic emergence of $\mathrm{O}_{2}$ on the Earth due to the movement of water is more and more evidence, and direct evidence of the formation of gases $\mathrm{H}_{2}$ and $\mathrm{O}_{2}$ [7] removed the last doubts. Probably, in case of a spill on water oil the fish dies because oil calms the sea, continuing education is necessary for life substances. In the beginning the Earth was not them. When icing the stationary ice does not allow them to appear. This conjecture has opponents. Exact origin of water on our planet, covering $71 \%$ of the surface is still a mystery to science. Suspect that the water of the Earth for 4.5 billion years would evaporate, the water came later. when massive celestial bodies of the Solar system fell to the Earth. Perhaps they had the water (but why it there wasn't evaporated?), could deliver it to us. Comets with tails of ice did it too. But here a trouble: in their water more of deuterium! The Earth's water is not from them, but our own, Earthly Nature. Space is full of $\mathrm{H}_{2}$, it is in the formation of hot celestial bodies reacts with all other elements, and $\mathrm{O}_{2}$ couldn't remain at high temperatures and an excess of $\mathrm{H}_{2}$. During the cooling of the planet's water is frozen and ice as light substance covered the surface of the Earth. But the core processes of Land given to volcanoes with the content of gases-oxides of $\mathrm{C}$, $\mathrm{S}, \mathrm{N}$. They created a layer of the atmosphere called the greenhouse effect, the ice was melting, and shakes of water was given oxygen and, therefore, the life. The water of the oceans is $71 \%$ of the Earth's surface and ranges round always at any time of the year. Added movements of water in clouds, rivers, waterfalls, avalanches. Water the world's oceans are in constant motion. Avalanches of ice also give rise to $\mathrm{O}_{2}$. From the friction of the ice in the spring ice drifts, the air is richer with oxygen, ozone. Easier to breathe near waterfalls, fountains, embankments. Mobile water wilts to the depths of the Earth, the reactions with hot carbides giving the oil, as demonstrated by Mendeleev. The usual theory of oil from dead plants is questionable. The depth of oil is high and it is difficult to imagine lungs of the plants got there. The richness of oil by sulfur compounds, which are not plants, said the weakness of traditional theories. Processes of volcanic eruptions, earthquakes associated with the chemical processes between water and hot in the bowels of Earth substances. Water is creator of geological processes. Displacements, disappearances or appearances of continents, Islands speak about the role of moving water. Due to the motion of the water, there is a unique Sargasso Sea without shores with a high level of water. Soft water breaking the rocks, created the mighty Niagara Falls and the Grand Canyon of Colorado. What does tsunami! Museums of natural beauty created by the water movement under the name "Karst phenomena". Surprising similarities are located on different sides of the Earth Australia and Greenland. In the mid of Australia is a desert without vegetation and greens only on the banks in the periphery, in Greenland, a desolate glacier in the center and green around the edges, which gave the name to the continent. Only water movement was spared, and its absence led to the death of all living things. Archaeology says that the Desert "Sahara" in Africa was blooming with a mild climate and there was water. The desert was the result of man-made disaster. Now disappeared Aral Sea. Disappearing marshes and rivers. Changing their directions. Creating seas. The Nature grew "assistant". In Sukhumi monkey's nursery among the rich subtropical vegetation was the land plot. Freedom, democracy, individual rights. So there is not a single petal of grass. Bare soil polished. Reminiscent 
of converting water, flora, fauna, no sphere, atmosphere, space. It is hoped that Nature will repent its child, Homo sapiens, and the movement of water will keep $\mathrm{O}_{2}$ from extenuating by machines, furnaces. Insights: Reveal the mechanism of the appearance of the Earth's oxygen, revealed the reason for the persistence of hydrogen peroxide in water. In Nature everything is interconnected, the division of natural philosophy into science is just a testament to our limited knowledge. Mechanics (physics) leads to the processes of transformation of water (chemistry) to substance necessary for life (biology) and global processes of the Earth (Geology).

Thus, the water behavior both in inorganic processes, as well as in living nature, confirms idea of unity laws for "living" nature ("ecosystems") and "non-living" objects ("environment"). The emergence of the Sahara Desert on earth is instructive. It, lifeless, occupies $1 / 3$ of the area of Africa. And continues to steadily grow. But historical research suggests that it was not a desert, without inhabitants, animals, plants, water. Previously, there were rainforests with the darkness of elephants, leopards, a network of rivers and lakes. Tired caravans of goods crossed the Sands in a variety of directions. And now over Sahara wide hot dry thin dust. The air temperature is about $+50^{\circ} \mathrm{C}$, and daytime heat changes the night cold with a drop of $35^{\circ} \mathrm{C}$. Constant drought and years in which the rain drops dry on the way, but if allowed to reach the ground, absorbed in the sand, and the depth form the reservoirs. From them there are oases. Archaeological excavations have revealed the images and inscriptions, saying that thousands of years ago there were deep rivers, thick grasses, herds of giraffes, elephants, antelopes, buffaloes, rhinos, lions. People destroyed the generosity of Nature-without measure hunted, fished, kept cattle, settled on the rivers. So with their own hands created an environmental disaster, the possibility of such constantly remind ecologists, but the Democrats with a thirst for profit do not hear it. We must not destroy the fragile ecosystem. Nature will not abolish the death penalty for his death. Sugar could become Paradise-a lot of light, heat, mineral salts. But there is no water, and life without it is impossible. The idea environmentalists are constantly working on finding ways of returning the Sahara to its previous terms of the cultivation of forests, the roots hold moisture. But while Sahara continued the offensive, moving toward the equator. Nature should be helped, not hindered.

\section{Physical Processes in The Movement of Water}

M. Folmer [8] said: "In contrast to the biological analogy in the formation of crystalline embryos is "spontaneous". Is this true? For example, water, whose polymers are exposed to the structure of the boundary phases, consider the problem of the emergence and growth of new phases in the system ice/water. Believed that ice is slippery because that pressure melts. But ice is at low temperatures, when the pressure is not enough for phase transition. A thin layer of water on the ice surface always exists. Surface struc- ture is different from bulk due to contact with an any environment. At the movement processes and changes in the structure of the clusters are active on the phase boundary. Structures and on them happening effects depends on external substances and energy effects. The "tin plague" comes at the germ which is isomorphic to $\alpha \mathrm{Sn}, \mathrm{InSb}, \mathrm{CdTe}$. Infection at a distance [9], is possible too, as by contact with an inert substance, earlier contacted the seed [10], infects only in the presence of water vapor [11]. In a vacuum no infection even with a pressing of the seed to the tin by "crocodile", so $\mathrm{Sn}$ covered with a layer of oxide. Stable below $-120^{\circ} \mathrm{C}$ ice $\mathrm{I}_{\mathrm{c}}$ is isomorphic with the structure of $\alpha \mathrm{Sn}$ and equal a lattice, epitaxial gives the seed in Nano quantities, is able to reach the surface of the tin through Nano-defects in the $\mathrm{SnO}$ due to the size of water molecules. Treatment by substance, the solvent of the I, remove it in the desiccator, vacuum, infection doesn't. It is natural to expect impossibility of infection under the water. But it happens after $\sim 1$ year, but only with shaking [4]. Water is formed an epitaxial structure the seed and held it under ice [12] The growth of $\alpha \mathrm{Sn}$ when infected behind the appearance of the germs, because growing a polycrystalline powder. But rare in water $I_{c}$ gives a small number of embryos, rate of growth above the rate form of new. From any crystals $\beta$ Sn single germ give single crystal $\alpha$ Sn (Figure 3 ) Single crystal $\alpha \mathrm{Sn}$ grows from the any $\beta \mathrm{Sn}$ crystals of any orientation. Ultrasound reduces the time of infection under the water from $\sim 1$ year to some minute, but the abundance of embryos gives the powder $\alpha \mathrm{Sn}$. Thus, the water behavior both in inorganic processes, as well as in living confirms idea of unity laws for "living" ("ecosysems") and "aliving" objects ("environment").

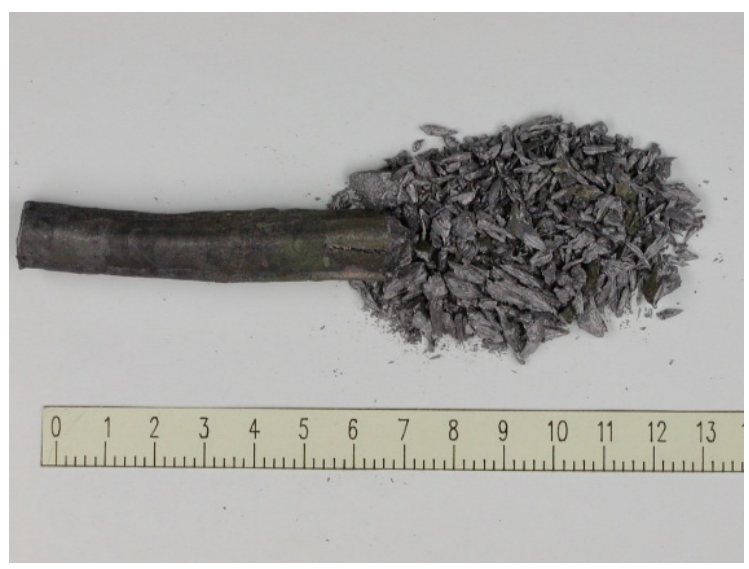

Figure 3: Monocrystal $\alpha \mathrm{Sn}$ growth under water in jacket of ice (left) after removal of ice number of embryos multiplies, giving polycrystal (right side of the figure).

There is the nature of the long-known mysterious of tin became clear, and infection under water allowed to give methods of obtaining single crystals of the interesting narrow-band semiconductor $\alpha \mathrm{Sn}$, previously known only as a powder, and its effective purification, and production of Sn powder of the set dispersion and 
purity [13]. But in the absence of water movement, these processes cannot occur.

\section{Chemistry Processes at the Water Movement}

In order to check the hypothesis about the character of the "behavior" of water during its mechanical movement performed measurements of Red-Ox potentials. Studied water distilled, dissolved gases removed. The reciprocating motion of the water with a specified frequency or with a relay, or the movements of a task portion water with time-delay switch was make on by means of a dose that allowed to vary the frequency of the same portion of water in vessel. $\Delta \mathrm{E}$ of a glass electrode ESL $48-11$, or $\Delta \mathrm{E}$ of $\mathrm{Pt}$ and $\mathrm{Pt} / \mathrm{q}$-h (quinhydrone, $\mathrm{C}_{6} \mathrm{H}_{4} \mathrm{O}_{2} 1: 1 \mathrm{C}_{6} \mathrm{H}(\mathrm{OH})_{2}$ ) electrodes (Figure 4) $\Delta \mathrm{E}, \mathrm{mV}$ t, $\mathrm{s}$

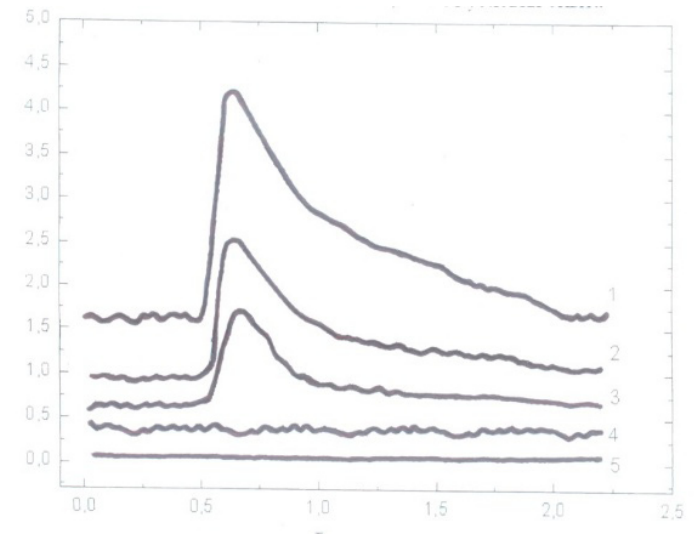

Figure 4: The changes of the $\mathrm{E}, \mathrm{mV}$ in time with a single push in the water (Curve1), or with $\mathrm{HCl}$ additives (Curve 2), or quinhydrone (Curve 3), or both of them (Curve 5) (There is no signal). Curve 4 shows the curve without shock. This is electrolytic dissociation pure water by temperature fluctuations.

Again, Saturated Calomel Electrode (SCE) by a "METEX» ME-31 voltmeter was noted manually or with H307/1 plotter continuously. Processes conducted in low ambient light. Reduced $\mathrm{pH}$ of the glass electrode when rolling the vessel manually at $2 \mathrm{~min}$. $\mathrm{pH}$ was decreased by 0.1 , and 5 minutes of rest, the $\mathrm{pH}$ returned to the original. Water movement was not on electrodes comparison. Indicated electrode shake with the vessel of water, or was fixed, but by shake water washed. (Figure 4)

Shaking for the long-time lead to rise of the potential of electrode. due to the accumulation of reaction products. After the stop shaking the $\Delta \mathrm{E}$ relaxes, reaching almost the initial values. The same behavior of the potentials of any electrodes. Growth $\Delta \mathrm{E}$ comes from fluctuations of the water independently of the presence of the electrodes. On the contrary, the electrodes catalyze the reverse process of relaxation, and, for example, Pt stronger than $\mathrm{Sn}$. This is due to a change in the concentration of decay products as a result of mechanochemical processes on the Red-Ox prod- ucts and the growth of its dissociation to ions. Earlier was noted a significant increase in $\left[\mathrm{H}^{+}\right]$by action of the shock wave. The presence $\mathrm{Pt} / \mathrm{q}-\mathrm{h}$ hides the formation of small amounts of new Red-Ox products and is visible only to the $\mathrm{pH}$ change (Figure 4, Curve 3). Similarly, when excess acid without Pt/q-h visible growth Red-Ox products (Figure 4, Curve 2) Established the creation of $\mathrm{H}_{2} \mathrm{O}_{2}$ at stoolies and proposed their hypothesis of creation in the nature of $\mathrm{O}_{2}$ due to mechanical decay of water [6]. Shows the persistence of hydrogen peroxide in rain, rivers, oceans, regardless of the impurity composition of the atmosphere [1,2]. The common changes of Red-Ox potential (Figure 4, curve 1) is equal to the sum of two nearly equal peaks, which appears at the addition of $\mathrm{HCl}(\mathrm{pH}=3)$ (curve 2) and q-h (curve 3) The background in the stationary water under joint presence of both supplements near the running relay, plotter, the doser $\sim$ is 0 (Figure 4, curve.5). Experiments with a long hesitation, give savings more products and return to the original potential longer (figure 5)

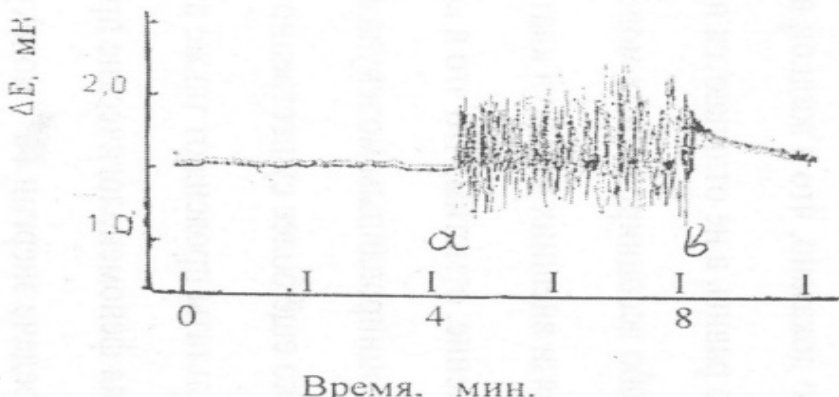

Figure 5: It shows the behavior of the potential of the Pt electrode in the water from its $\mathrm{E}$ without shocks first, then change it from include (a) to off (b), and relaxation of these products after (b) figure 5 shows experimental relaxation curve in the water.

It is clear that the emergence of Ox- products can't occur without the appearance of Red-products, as well as ions $\mathrm{H}^{+}$without $\mathrm{OH}^{-}$ions. the computer without any guidance in this regard is itself calculated from summary pair of relaxation curve products such as the assumption and the loss of ox products with reduction $(+)$ the values of $E$ and increase $(+)$ of Eat loss of ions. Summary kinetic of process is given by the equation $y=51,75$. $\mathrm{e}^{-0,0894 x+12,65}$ $\mathrm{e}^{0,0168 \mathrm{x}}$, representing the superposition of two exponentials of the recombination parts. Hydrated electron [13], that is, radical $\mathrm{H}^{*}$, or atomic H. the Polymers capable of chemical processes without compromising the conservation law [14]. The energy of the polymer is much greater than the energy of one H-O bond. The mathematical analysis of the relaxation curve confirms conclusion [5] that under water vibrations nothing but $\mathrm{H}_{2}$ and $\mathrm{O}_{2}$ gases is formed in the end and that the water decay follows the ways of breaking 


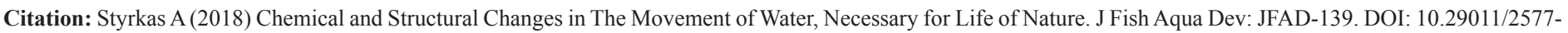
1493. 100039

the Oh-H bond with the preservation of the e: u pair and the formation of ions or breaking it with the formation of radicals, and the energy of breaking the bond is approximately the same, see figure 4 (Curve 2,3). Push formed Red-Ox products at pair of e: $\mathrm{H}: \mathrm{OH}$ chemical bonding gap with breaking pair of e: either to ions with the preservation of the pair eat the $\mathrm{O}\left(\mathrm{H} \div \mathrm{OH}=\mathrm{H}^{+}+\mathrm{OH}^{-}\right)$or with its rupture and the formation of radicals by $\mathrm{H} \div \mathrm{OH}=\mathrm{H}^{*}+\mathrm{OH}^{*}$ and a subsequent reactions of the radicals $2 \mathrm{H}^{*} \rightarrow \mathrm{H}_{2} ; 2 \mathrm{OH}^{*} \rightarrow \mathrm{H}_{2} \mathrm{O}_{2}$; $2 \mathrm{H}_{2} \mathrm{O}_{2} \rightarrow 2 \mathrm{H}_{2} \mathrm{O}+\mathrm{O}_{2}$. the Ratio $\Delta \mathrm{E}_{\text {radical }} / \Delta \mathrm{E}_{\mathrm{pH}} \sim 1$. Figure 4 show $\Delta \mathrm{E}_{\Sigma}$ arises due decay water on radicals and dissociation, and $\Delta \mathrm{E}_{\mathrm{pH}}$ from the growth of $\left[\mathrm{H}^{+}\right]$at a constant ratio $[\mathrm{Ox}] /[\mathrm{Red}]$ and therefore negligible additive $\Delta \mathrm{E}^{*}$ (Figure. 4 , Curve 2.) And $\Delta \mathrm{E}^{*}=0.5 \Delta \mathrm{E}_{\Sigma}$ also when in water there is excess of $\mathrm{H}^{+}$or $\mathrm{OH}^{-}$(Figure 4, curve 3 ). Equality of partial $\Delta \mathrm{E}$ and there $\Sigma$ to $\Delta \mathrm{E}_{\Sigma}$ indicates only one energy of gap $\mathrm{O}-\mathrm{H}$ and equal energy their chemical bonds! The same is said NMR spectrum with one and not the two types of bonds for $\mathrm{O}-\mathrm{H}$ contrary to the view, that covalent 10 times stronger than ionic bonding, which is correct in the case for gas molecules. The structure of water has no distinction ties H with "his" and "alien" $\mathrm{O}$ (as draw in textbooks to contrast the strong covalent bond ""weak hydrogen bond "**", $(\mathrm{H}-\mathrm{O} * * \mathrm{H})$ And it's the wrong current opinion for life hard to digest to the school-parrots, future reviewers, fighters with pseudoscience! A gap requires equal energy. If $\Delta \mathrm{E}_{\mathrm{pH}} / \Delta \mathrm{E}^{*}=0,1$ dissociation considerable would be more efficient then radical formation. In water hydrogen ties give unified energy system. Hydrogen bonds give unified energy system for a single polymer. Such they can take for other substances, but not for water. Benzene has 1 type of link, and in NMR only 1 line for C-C bond, not 2, as must be with the striping of single and double bonds. In ion $\mathrm{NH}_{4}^{+}$all $\mathrm{H}$ are identical and are arranged on the tops of a tetrahedron with $\mathrm{N}$ in the center, when gas $\mathrm{NH}_{3}$ molecule has the form of a trigonal pyramid with $\mathrm{N}$ at the top. The NMR spectrum also confirms this. Ion $\mathrm{HF}_{2}{ }_{2}$ paint as $\mathrm{F}-\mathrm{H}-\mathrm{F}$ (not as $\mathrm{F}-\mathrm{H}^{*} * \mathrm{~F}$ !) according to its properties and NMR spectrum. And keto-enola tautomeric is because the energetic position of the $\mathrm{H}$ atoms in the structure of the ketone or Enola on bond strength is almost equal. The same substance manifests itself anole or a ketone depending on the neighboring atoms in the molecule or an external reagent. But with leveled ties of water reviewers-parrots can't tolerate! This is natural, understandable all, but not to parrots.

The theorists from the spectra of single molecules calculated the bond $\mathrm{O}-\mathrm{H}$. A covalent tie due to the formation of an electronic pair $\mathrm{O}$ and $\mathrm{H}$, with the addition of electrostatic ion content $\sim 0.1$ of its magnitude. Other types of bonds are negligible. Theorists stressed that the calculations relate to single molecules of gas, not to condensed phases, but parrots memorized pictures and relates them to any form of water. Repeating a walking opinions of the same authorities, they becomes wise professors, reviewers, not seeing the difference between molecules and polymers, forming three-dimensional strong glass-type systems hydrogen bonds in the system due to the small size of $\mathrm{O}$ and $\mathrm{H}$ and the presence of two free electron pairs at $\mathrm{O}$. Solid journals accept lapses of the one who "knows", how pH to change not by fluctuations, but known other causes, and, therefore, "unscientific fluctuations of water", showing the $\mathrm{pH}$ and Red-Ox E changes at any mechanical processes, by them, is "any electrochemical trifle". Distinct experimental facts they declared as "pseudoscientific trifle". There is their wise wonderful scientific term. The noise (Figure 4, Curves 4,5) arises from the drift of temperature fluctuations. The noise drift of the curve.5 is lower than in curve. 4. It says that impact of temperature shakes leads to dissociation, mechanism is also due to mechanical effects. The model water in the gas laws for real solutions administered activity $\mathrm{a}=\mathrm{fc}$. Water has $\mathrm{f}=1, \mathrm{c}=\mathrm{const},[\mathrm{H}+] .[\mathrm{OH}-]=10^{-14}$ The laws of ideal gases applied to the infinitely diluted solutions. The real solutions have instead of concentrate to enter the activity, reducing difficulties to design of the activity coefficient $\mathrm{f}=\mathrm{a} / \mathrm{c}$. The physical meaning $\mathrm{f}$ as a consequence of the ion environment is clear. Deviations from the formulas for ideal gases fixed in the frame of the atomic-molecular model. Theory in the number of cases tolerably explains fakts, though liquids have a higher density than the gases, causing doubts about the applicability of the gas laws, even as amended. To ignore with impunity, the orientation of the bonds it is impossible. The theory of absolute speeds of reactions are absolutely unable to meet the experiment. As a weak mechanical impact lead to dissociation to ions? For it turns out that fluctuations of for 1 molecule will take energy from $10^{7}$ other. Science recognizes the presence of electrolytic dissociation of water, contrary to the calculations of the bond in the gas molecule. The credibility of Berzelius helped to admit to something that "can happen". "But if it there is, then it may be!" Think about this, reviewers, if you can! But they pighead: "If it were so, the atmosphere would be full of hydrogen! "Children know and about hydrogen-helium layer at $100 \mathrm{~km}$ under Earth, about the low $\left[\mathrm{O}_{2}\right]$ by walking in the mountains, but wise parrots of prestigious journals without experiment knows otherwise. The water is polymers; their ties $\mathrm{O}-\mathrm{H}$ ties are united with equal energy. (Figure 4, curve 2, 3) on radical pairs section e: between the $\mathrm{H}$ and $\mathrm{O}$ ions and retain it at $\mathrm{O}$ refutes opinion about the difference of energy of covalent and ionic bonding in water as in the gas. In $\left(\mathrm{H}_{2} \mathrm{O}\right) \mathrm{n}$ (if $\mathrm{n}=8$ and more) solvated e- is stable [13]. Analogues water $\mathrm{H}_{2} \ni$ from Te to $\mathrm{S}$ natural to decrease $\mathrm{T}$ boiling and melting. They suddenly sharply increase for water. Transport Number (TN) of ions of the 1st group reduced from Cs to Li, but increases sharply to H. "Anomalies" of different properties creates anomalous hydrogen bond of water. The atom $\mathrm{O}$ has 6 valences e/ 4 give 2 free pairs of e, 2 remaining gives valence bond with two $\mathrm{H}$. So in the molecule each $\mathrm{O}$ is donor of 2 e pairs for unoccupied levels. One proton can bind 2 neighboring water molecules. The sizes of $\mathrm{O}$ and $\mathrm{O}-\mathrm{H}$ are small and therefore give a polymer [5,13-15]. The $\mathrm{H}-\mathrm{O}-\mathrm{H}$ has not electrostatic $\left(180^{\circ}\right)$ or $\left(90^{\circ}\right)$ for $2 \mathrm{p}$ - electrons for angle between the links $\mathrm{O}-\mathrm{H}$, and has $104.5^{\circ}$. The structure of water polymer is not chaotic (as vapor), not sim- 
Citation: Styrkas A (2018) Chemical and Structural Changes in The Movement of Water, Necessary for Life of Nature. J Fish Aqua Dev: JFAD-139. DOI: 10.29011/25771493. 100039

ply tetrahedrically not dense pack (as ice). Short-range order is the same, but in the emptiness of the leaky lattice of secondary molecules are embedded, leading to growth $\mathrm{d}$ water in comparison with ice. Water this is a liquid glass, polymers up to $100 \mu[16,17]$, to describe their laws individual molecules-not seriously.

Model with a symmetric long-range Coulomb forces is also inadequate. Zone theory of common electrons in the area requires introduction of "effective mass"(me), (like $\mathrm{f}$ in the model of gas). But those calculations of the amendments permit to (me) accepts (-) value, and the length of the free path e to be smaller than the size of an atom, which is absurd. Pauling noted that theoretical physicist's solutions of the Schrödinger equation for any complex substances for such a long period there is no result, so we have to use reliable structural chemical representations. [18]. Both models for gases or metals with spherical symmetric forces are inadequate. The theory of socialization of the electrons in the zone requires amendment, but" effective mass", sometimes the host (-) values of no physical meaning. The zone model should be discarded. Thus, the water behavior both in inorganic processes, as well as in living nature, confirms idea of unity laws for "living" ("ecosysems") and "non-living" ("environment"). Anomalies of water strange laws strange to the laws of gases and crystals. So should look for other ways of model of the type of glass. Polymers have different structures; the movement leads to destruction. In the presence of other substances can occur in the metastable structure, remaining long enough and causing natural processes. Let us emphasize the feature of positive influence of water movement on natural processes. Very important appeared mechanochemical products. But no less important is the property of polymers in collisions change. They change their structure near the matrices, are building new structures in their image. The water in man and fish are structured differently. Therefore, in the presence of seed at a distance or on an inert substance water vapor build them a similar structure and cause infection Sn [4-8] in inanimate Nature, as a living, to create a new phase requires a germ. They are different for tin, Kalanchoe, elephant, although they are created from the same water. Distorted mechanical polymers are built on the matrix, the healthy cells of the body are built on the site of the affected patient structures necessary healthy. The behavior of water in moving processes confirms unity laws for ecosystems and environment.

\section{References}

1. Chameides WL, Davis DD (1982) The free radical chemistry of cloud droplets and its impact upon the composition of rain. J Geophys Res 87: 4863-4877.
2. Zika RG, Saltzman ES, Chameides WL, Davis DD (1982) J Geophis Res 87: 5015-5017.

3. Davydov AS (1984) Solitons in molecular systems. K Naukova Dumka 208.

4. Styrkas AD (2003) Infection of Tin in Liquid Water. Inorgan Mater 39: 940-943.

5. Styrkas AD (2003) The growing crystals of gray tin. Inorgan materials 39: $683-686$

6. Domrachev GA, Rodygin Yu JL, Selivanovsky DA (1993) Mechanochemical activated decomposition of water in liquid phase. DAN USSR, Phsical chemistry 186-188.

7. Styrkas AD (2011) The study of the composition of gas products formed during oscillatory movements of water. J Inorganic Chemistry 56: $1092-1094$.

8. Volmer M (1986) Kinetics of the formation of a new phase. M Science.

9. Aptecar IL, AD Styrkas (1982) Contamination of tin in the distance. DAN USSR 5: 1155-1157.

10. Aptecar IL, Styrkas AD (1993) Inert substrate like vectors tin plague from InSb for Sn. High-purity substances 3: 56-60.

11. Aptecar IL, Styrkas $A D(1987) \mathrm{H}_{2} \mathrm{O}$ - the causative agent of plague tin. DAN USSR 5: 1149-1151.

12. Styrkas AD (2016) Life, Memory, Recognition and Aging of Grey Tin. Journal of Mater Science and Chem Engineering 4: 1-11.

13. Novakovskaia YV, Stepanov NF (2000) Hydrated electron AB initio modeling. J Physical Chemistry 74: 71-79.

14. Fomin VN (2004) The Impact of mechanical treatment on the formation of properties of multicomponent systems. M Science 82.

15. Bernal D, Fowler R (1934) The Structure of water and ionic solutions. Sucsess Phys Sc 14: 1312-1324.

16. Smirnov AN, Syroeshkin AV (2004) Supramolekulyar complexes of water. Ross Chem J 48: 125-135.

17. Smirnov AN, Lapshin VB, Balashev AV, Labedev IM, Goncharuk VV, et al. (2005) water Structure giant heterophase clusters of water. Chemistry and technology of water 2: 11-37.

18. Pauling $L$ (1960) The nature of chemical bond. 3: 220 . 